\title{
OUVIDORIA-GERAL DO ESTADO DE PERNAMBUCO: ANÁLISE DOS RELATÓRIOS DE GESTÃO DA SECRETARIA ESTADUAL DE EDUCAÇÃO (2015- 2019)
}

\author{
DEFENSORÍA GENERAL DEL ESTADO DE PERNAMBUCO: ANALISIS DE LOS \\ INFORMES DE GESTIÓN DE LA OFICINA DE EDUCACIÓN (2015-2019)
}
GENERAL OMBUDSMAN OF THE STATE OF PERNAMBUCO: ANALYSIS OF THE MANAGEMENT REPORTS REGARDING THE STATE SECRETARIAT OF EDUCATION (2015-2019)

\author{
Dayzi Silva OLIVEIRA ${ }^{1}$ \\ Ana Lúcia Borba de ARRUDA ${ }^{2}$
}

RESUMO: O presente trabalho tem como objetivo analisar os relatórios de gestão da Ouvidoria-Geral do Estado de Pernambuco (OGE) que contemplam dados da Secretaria de Educação (SEE-PE) entre o período de 2015-2019 tendo como foco a natureza das manifestações e como estas são organizadas e apresentadas. Teve como base metodológica pesquisa dos documentos e leituras bibliográficas (BORDENAVE, 1994; DEMO, 1993; GOHN, 2019; LAVALLE, 2015). Os resultados mostraram as possibilidades das ouvidorias públicas como um espaço de participação, todavia, demandam ações ampliadas, entre outras, de transparência ativa e organização das informações disponibilizadas.

PALAVRAS-CHAVE: Ouvidoria. Educação. Participação.

RESUMEN: Este trabajo tiene por objeto analizar los informes de gestión de la Oficina del Defensoría General del Estado de Pernambuco (DGE que incluyen datos da Secretaría de Educación (SEE-PE) entre el periodo de 2015-2019, centrándose en la naturaleza de las manifestaciones y cómo se organizan y presentan las informaciones. Tuvo como base metodológica la investigación de los documentos y lecturas bibliográficas (BORDENAVE, 1994; DEMO, 1993; GOHN, 2019; LAVALLE, 2015).Los resultados mostraron las posibilidades de las defensorías públicas como espacio de participación, sin embargo, exigen acciones ampliadas, entre otras, de transparencia activa y organización de las informaciones puestas a disposición.

PALABRAS CLAVE: Defensorías. Educación. Participación.

\footnotetext{
${ }^{1}$ Universidade Federal de Pernambuco (UFPE), Recife - PE - Brasil. Pesquisadora do Observatório de Política e Gestão da Educação (OBSERVA/UFPE). Mestrado em Educação (UFPE). ORCID: https://orcid.org/0000-00029936-0983. E-mail: dayzi.oliveira@ufpe.br

${ }^{2}$ Universidade Federal de Pernambuco (UFPE), Recife - PE - Brasil. Professora Associada do Departamento de Administração Escolar e Planejamento Escolar e do Programa de Pós-graduação em Educação. Doutorado em Educação (UFPE). ORCID: https://orcid.org/0000-0002-9059-0483. E-mail: ana.barruda@ufpe.br
} 
ABSTRACT: This present study aims to analyze the management reports of the General Ombudsman from the State of Pernambuco (OGE), that contemplate data of the Secretariat of Education (SEE-PE) between 2015-2019, focusing on the nature of the manifestations and how they are organized and presented. The study had as methodological basis the search for documents and bibliographic readings (BORDENAVE, 1994; DEMO, 1993; GOHN, 2019; LAVALLE, 2015). The results demonstrated the possibilities of the public ombudsmen as a space of participation, although they demand expanded actions, among others, of active transparency and organization on the information available.

KEYWORDS: Ombudsman. Education. Participation.

\section{Introdução}

Desenvolver reflexões teóricas e delimitadas sobre ouvidorias públicas não é fácil, tendo em vista ser um tema que envolve amplas e densas categorias. Lavalle (2011, p. 36) destaca que "há hoje forte descompasso entre a riqueza das experiências participativas no país e a precariedade do nosso conhecimento sobre seus efeitos".

A Escola Nacional de Administração Pública (ENAP) define ouvidorias públicas como um instrumento de participação a serviço da democracia; mais especificamente, as ouvidorias encontram na democracia o campo necessário para sua expansão e fortalecimento, uma vez que devem ser compreendidas como espaços plurais, abertos à mediação e à resolução das demandas dos cidadãos (ENAP, 2017). Com efeito, Gomes (1996, p. 124) destaca que as ouvidorias públicas têm como objetivo viabilizar o "necessário espaço para o pleno exercício do direito de avaliação e controle da gestão pública, requisito indispensável para a consolidação da nossa democracia".

Uma das particularidades das ouvidorias públicas são as categorias de manifestações, isto é, a classificação dos conteúdos demandados pelos cidadãos. Através da instrução ${ }^{\circ}$ 01/2014 da Ouvidoria-Geral da União (OGU), ligada à Controladoria-Geral da União (CGU), as ouvidorias do Poder Executivo federal adotam cinco tipos de manifestação: as reclamações, que têm como particularidade a comunicação da insatisfação com o serviço público; as denúncias, ou seja, a comunicação de ato ilícito; sugestões, o indicativo de propostas de melhorias de políticas e serviços prestados pela administração; elogios, a demonstração de satisfação com os serviços recebidos; e solicitações, que são os requerimentos de informações. A Secretaria de Educação de Pernambuco (SEE-PE) adota os cinco tipos de manifestações em sua ouvidoria, alinhada com a Ouvidoria-Geral do Estado de Pernambuco (OGE). 
O artigo analisa os relatórios de gestão da Ouvidoria-Geral do Estado de Pernambuco (OGE) que contemplam dados da Secretaria de Educação de Pernambuco (SEE/PE) entre o período de 2015 a 2019 buscando apreender a natureza das manifestações e como estas são organizadas e apresentadas à sociedade. $\mathrm{O}$ embasamento teórico se dará em duas categorias gerais: Ouvidorias Públicas e Participação. O debate sobre participação é amplo, assim, o recorte bibliográfico para apreensão basilar dar-se-á com autores, como Bordenave (1994, Demo (1993) Gohn (2007; 2019), Lavalle (2015). Os referenciais sobre Ouvidorias Públicas serão: Vaz e Pires (2010), Pinto (2009) e Cortes (2015), além dos indicativos jurídicos, matérias e cartilhas orientadoras presentes no sítio eletrônico da Ouvidoria-Geral do Estado do Pernambuco (OGE/PE) e da Controladoria-Geral da União (CGU) e dos materiais disponíveis pela Escola Nacional de Administração Pública (ENAP).

A produção de caráter exploratório permite ao pesquisador, conforme Gil (2002, p. 41), o aprimoramento das ideias ou a descoberta de intuições. Seu planejamento é, portanto, bastante flexível, de modo que "possibilite a consideração dos mais variados aspectos relativos ao fato estudado". No contexto da pesquisa exploratória (quanto aos seus objetivos), mais especificamente a natureza das fontes, teremos a etapa definida como pesquisa bibliográfica. Também, far-se-á presente a pesquisa documental, como sinaliza Severino (2007, p. 122), "tem-se como fonte documentos no sentido amplo, ou seja, não só documentos impressos, mas sobretudo de outros tipos de documentos, tais como jornais, fotos, filmes, gravações, documentos legais".

\section{Por uma definição de Ouvidoria Pública}

Para Cortes (2015), existem quatro tipos básicos de Instituições Participativas (IPs) nos municípios brasileiros; entre eles, estão as ouvidorias, que são "os canais de expressão individual de preferências como pesquisas de satisfação, serviços que recebem demandas, sugestões ou reclamações por telefone ou via internet, ouvidorias; processos conferencistas; orçamentos participativos (OPs); e conselhos de políticas públicas e de direitos" (CORTES, 2015, p. 81, grifos nossos). Para este autor, Instituições Participativas (IPs) são instituições criadas por lei, emendas constitucionais, resoluções ou normas administrativas governamentais que possibilitam o envolvimento regular e continuado de cidadãos com a administração pública, mais especificamente:

São instituições porque não se constituem em experiências episódicas ou eventuais de participação em projetos ou programas governamentais ou de 
organizações da sociedade civil ou do mercado. Ao contrário, estão instituídas como elementos característicos da gestão pública brasileira. Diferem dos modos de participação eleitoral típicos das democracias liberais, ao permitir a representação de interesses e a expressão de preferências ao longo de legislaturas, entre os períodos eleitorais (CORTES, 2015, p. 139).

Assim, é possível definir as ouvidorias públicas como um tipo de Instituição Participativa (IP), sendo um canal de expressão individual de preferência. Como destaca Nascimento (2012, p. 71, grifo nosso), "a ouvidoria, nesse contexto, enquanto mecanismo de efetivação do direito, busca garantir para a coletividade, através da busca individual do cidadão, o eficaz e efetivo cumprimento dos seus direitos garantidos pelo Estado".

Uma das particularidades das ouvidorias públicas é que muitas vezes elas são tomadas, como destacam Neto e Durán (2016), apenas como receptores de reclamações da sociedade. Todavia, os autores entendem a legitimidade das ouvidorias públicas "como protagonistas na promoção da cidadania, isto é, uma postura proativa em que as ouvidorias são tomadas como instrumentos da democracia participativa destinados a cumprir funções de mediação entre a sociedade e o poder público" (NETO; DURÁN, 2016, p. 71).

Posto isso, embora a presença jurídica ateste a necessidade de instrumentos de participação entre cidadãos e Estado na Administração Pública, o problema de instituições participativas como as ouvidorias públicas é que "são raros os estudos que visam avaliar se e como tais instituições participativas produzem impactos sobre a atuação de governos, isto é, sobre a gestão pública e sobre a produção de políticas públicas" (VAZ; PIRES, 2011, p. 5). Deste modo, um dos desafios (e ausências) dos estudos sobre ouvidorias públicas são os seus impactos na Gestão Pública enquanto instrumento de participação.

É importante destacar que entendemos as ouvidorias como uma ação do Estado que envolve distintos atores políticos em um contexto histórico e social. Ou melhor, compreendemos as mesmas, como destaca Jardim, Silva e Nharreluga (2009), como uma política pública informacional, ou seja, como um conjunto de decisões e ações produzidas pelo Estado e inseridas nas agendas governamentais em nome do interesse social que contempla diversos aspectos (administrativo, legal, científico, cultural, tecnológico etc.) relativos à produção, uso e preservação da informação de natureza pública e privada. As políticas públicas são aqui compreendidas, com base em Hofling (2001, p. 31), como de responsabilidade do Estado quanto à implementação e manutenção, "a partir de um processo de tomada de decisões que envolvem órgãos públicos e diferentes organismos e agentes da sociedade relacionados à política implementada". 


\title{
Ouvidora-Geral do Estado de Pernambuco (OGE)
}

Em Pernambuco, foi adotado um forte modelo de gestão gerencialista, principalmente nos governos estaduais de Jarbas Vasconcelos e de José Mendonça Filho, que promoveram uma grande reforma no estado, através do Decreto $\mathrm{n}^{\circ} 22.730$, de 18 de outubro de 2000, em que foi instituído o Programa Pernambucano de Modernização da Gestão Pública (PROGESTÃO), com a finalidade de promover a modernização gerencial das instituições públicas da administração direta e indireta no estado.

Como afirma Lima (2008), ao que remete às ouvidorias, o governo da época propôs a implantação de unidades de ouvidorias no serviço público em todas as 40 instituições como forma de manter o canal de diálogo e o foco das atenções no cidadão-usuário, alvo das ações no serviço público. Em novembro do mesmo ano, a Lei Estadual $n^{\circ} 12.452$, de 05 de novembro de 2003, que se refere à proteção e defesa do usuário dos serviços públicos prestados pelo estado de Pernambuco, no seu parágrafo $1^{\circ}$ do art. $8^{\circ}$, destacou que, para assegurar ao cidadão o controle adequado do serviço, autoriza a instituição de ouvidorias em todos os órgãos e entidades prestadoras de serviços públicos no Estado de Pernambuco. Assim, em dezembro de 2004, foi, então, elaborado pela equipe do PROGESTÃO um Plano de Implantação de Ouvidorias:

\begin{abstract}
Para a elaboração desse plano foram contratados os serviços da AXON Tecnologia da Informação e Gestão através do contrato 0018/2006. Esse contrato foi firmado com o Programa de Educação de Qualidade - EDUQ, dentro do Programa de Modernização Administrativa e Gerencial do Governo de Pernambuco, em específico na Secretaria de Educação através do componente de Modernização do Sistema de Educação, Cultura e Esportes, que teve o objetivo de desenvolver e implantar processo de reforma e modernização administrativa e gerencial na Secretaria. Esse foi um dos trabalhos financiados pelo Banco Mundial e previa utilizar essa experiência como modelo para desenvolver e disseminar novas tecnologias de gestão em toda administração pública estadual. Dentro desse contexto a efetividade da Ouvidoria foi uma das linhas de ação programáticas a ser desenvolvida pela Secretaria de Educação, Cultura e Esportes - SEDUC e a Secretaria de Administração e Reforma do Estado SARE. Em relação ao financiamento acima referido, o Sr. Jader Toscano, que até o final de 2006 desempenhava a função de Ouvidor da Secretaria da Fazenda e hoje é o Ouvidor da Secretaria de Educação destacou que este financiamento seria destinado para a implantação de um modelo de Ouvidoria na Secretaria de Educação para replicar para todo Estado (LIMA, 2008, p. 71, grifo nosso).
\end{abstract}

A partir disso, podemos fazer reflexões importantes. Como afirma Castro (2008), o gerencialismo caracteriza-se pela busca da eficiência, pela redução e pelo controle dos gastos 
públicos, pela demanda de melhor qualidade dos serviços públicos, pelos modelos de avaliação de desempenho, "por suas novas formas de controlar o orçamento e os serviços públicos e pela descentralização administrativa, que dá maior autonomia às agências e aos departamentos" (p. 391).

Portanto, na gênese expansiva das ouvidorias em Pernambuco, o contexto do discurso da modernização da gestão demandou a contratação de uma empresa privada e o foco na descentralização. Assim, uma das características da reestruturação do sistema capitalista é "a procura da eficiência e da produtividade [que] levou os responsáveis pela administração pública a buscarem, na iniciativa privada, uma nova forma de organização e gestão para os serviços públicos." (CASTRO, 2008, p. 390). Dito isso, é possível observar semelhanças com esse movimento, inclusive pelo fato de ser um trabalho financiado pelo Banco Mundial, que, como afirma Soares (1996), exerceu "profunda influência nos rumos do desenvolvimento mundial. Sua importância hoje deve-se não apenas no volume de seus empréstimos, mas também ao caráter estratégico que vem desempenhando no processo de restruturação neoliberal." (SOARES, 1996, p. 15). Portanto, as inter-relações mostram os movimentos de um processo hegemônico do gerencialismo no Estado alinhado aos pressupostos neoliberais; no entanto, toda pesquisa precisa levar em consideração as particularidades locais.

Seguindo os movimentos da implementação da ouvidoria local, no mês de novembro de 2006, foi entregue ao governo o relatório final da Consultoria AXON, contemplando o Modelo Conceitual a ser implantado nas Ouvidorias das secretarias estaduais e órgãos vinculados. O modelo apresentado pela empresa estabeleceu as "bases de referência para o desenho e a operação do Sistema de Ouvidoria no âmbito do Governo do Estado" (LIMA, 2008, p. 72). Quanto à organização interna, o relatório apresentou uma estrutura enxuta, podendo contar com ouvidor, atendentes, auxiliares ou secretária. O documento da AXON também destacou a importância de "se assegurem os canais de acesso à Ouvidoria de forma distribuída, seja com o uso de caixas de mensagens, linha 0800, sites, ou outras formas, garantindo com isso a facilidade de contato" (AXON, 2003, p. 18 apud LIMA, 2008).

Conforme informações disponíveis no site da instituição, a Ouvidoria-Geral do Estado de Pernambuco (OGE) tem como objetivo fortalecer a cidadania, aproximar o cidadão da gestão pública estadual e contribuir com a melhoria contínua dos serviços públicos prestados à sociedade. A Ouvidoria é vinculada à Secretaria da Controladoria-Geral do Estado (SCGE) e é responsável por receber, examinar e encaminhar sugestões, elogios, solicitações, reclamações e denúncias aos órgãos e entidades responsáveis por adotar as devidas providências, sendo descrita como um importante dispositivo de controle social. A sua missão 
é: ser um canal de manifestação e representação dos interesses dos cidadãos, no que tange à administração pública e à busca de sua melhoria.

\section{Ouvidoria: uma possibilidade de participação?}

Entendidos os elementos importantes das ouvidorias públicas em seus movimentos históricos, conceituais e locais, segue o ponto que remete à participação. Como aponta Gohn (2019), a temática é ampla e pode ser observada tanto do ponto de vista das práticas civis efetivas como do ponto de vista de estudos e pesquisas de analistas de diversas áreas. A autora sinaliza que participação é uma das palavras mais utilizadas no vocabulário político, científico e popular, "dependendo da época e da conjuntura histórica, ela aparece associada a outros termos como democracia, representação, direitos, organização, conscientização, cidadania, solidariedade, exclusão etc. Vários foram os teóricos que fundamentaram o sentido atribuído à participação" (GOHN, 2019, p. 64).

Através do campo conceitual, Gohn (2007) apresenta o entendimento de participação através de várias perspectivas, como a liberal, que tem como definição de participação o fortalecimento da sociedade civil para evitar a ingerência do Estado, baseada no princípio de que todos os membros da sociedade são iguais; a autoritária, que entende participação como processo de integração e como controle social da sociedade e da política; a revolucionária, na qual coletivos são organizados para lutar contra as relações de dominação e pela divisão do poder político, com destaque e importância para os sistemas partidários; a democrática, em que a participação se desenvolve na sociedade civil e nas instituições formais políticas (exemplo, sistemas representativos via processos eleitorais); e, por fim, a democrática radical, que, de acordo com Gohn (2007, p. 19):

Fortalece a sociedade civil para a construção de caminhos que apontem para uma nova realidade social, sem injustiças, exclusões, desigualdades, discriminações etc. O pluralismo é a marca dessa concepção. Os partidos políticos não são mais importantes que os movimentos sociais, e os agentes de organização da participação social são múltiplos. Uma gama variada de experiências associativas é considerada também relevante no processo participativo, tais como grupos de jovens, de idosos, de moradores de bairros etc. Os entes principais que compõem os processos participativos são vistos como "sujeitos sociais". Não se trata, portanto, de indivíduos isolados nem de indivíduos membros de uma dada classe social. A participação tem caráter plural. Nos processos que envolvem a participação popular, os indivíduos são considerados "cidadãos". A participação articula-se, nesta concepção, com o tema da cidadania [...] A participação envolve também lutas pela divisão das responsabilidades dentro do governo. Essas lutas possuem várias frentes, tais como a constituição de uma linguagem 
democrática não-excludente nos espaços participativos criados ou existentes, o acesso dos cidadãos a todo tipo de informação que lhes diga respeito e o estímulo à criação e desenvolvimento de meios democráticos de comunicação.

Concordamos com a autora e entendemos, como exemplo, que as ouvidorias são um dos meios democráticos de comunicação, tendo em vista que as informações geradas pelos cidadãos podem ser usadas para melhorar os serviços públicos, solicitar mudanças, mas sempre articuladas com outras estratégias, em diversas frentes, inclusive os sindicatos.

Outra definição, como destaca Lavalle (2011), é de que a participação pode ser apreendida como uma categoria nativa da prática política de atores sociais; uma categoria teórica da democrática, com pesos variáveis segundo as vertentes teóricas e os autores; e um procedimento institucionalizado, com funções delimitadas por leis e disposições regimentais. A autora também destaca a multidimensionalidade ou polissemia dos sentidos práticos, teóricos e institucionais que torna a participação um conceito fugidio não apenas em decorrência de que a aferição de efeitos "é operação sabidamente complexa, mas devido ao fato de sequer existirem consensos quanto aos efeitos esperados da participação, ou, pior, quanto à relevância de avaliá-la por seus efeitos" (LAVALLE, 2011, p. 33).

Milani (2008) destaca que a participação é integrante da realidade social, onde as relações sociais são baseadas em estruturas. Para a autora, "sua ação é relacional; ela é construção da/na transformação social. As práticas participativas e suas bases sociais evoluem, variando de acordo com os contextos sociais, históricos e geográficos.” (p. 560).

Já outro autor, Pedro Demo (1993), entende participação como processo, como um constante vir-a-ser, onde os espaços de participação precisam ser conquistados e que todos os processos participativos profundos tendem a ser lentos. Para ele, "participação é em essência autopromoção e existe enquanto conquista processual. Não existe participação suficiente e acabada. Participação que se imagina completa, nisto mesmo começa a regredir" (DEMO, 1993, p. 18). Defendendo a participação como processo, o autor destaca que:

A participação não pode ser entendida como dádiva, como concessão, como algo já preexistente. Não pode ser entendida como dádiva, porque não seria produto de conquista, nem realizaria o fenômeno fundamental da autopromoção; seria de todos os modos uma participação tutelada e vigente na medida das boas graças do doador, que delimita o espaço permitido. Não pode ser entendida como concessão, porque não é um fenômeno residual ou secundário da política social, mas um dos seus eixos fundamentais; seria apenas um expediente para obnubilar o caráter da conquista, ou de esconder, no lado dos dominantes, a necessidade de ceder. Não pode ser entendida como algo preexistente, porque o espaço de participação não cai do céu por descuido, nem é o primeiro passo (DEMO, 1993, p. 18). 
Bordenave (1994) sinaliza que a participação, diante dos diversos sentidos atribuídos a ela, tem como objetivo final a "autogestão", ou seja, uma autonomia dos grupos populares organizados em relação aos poderes do Estado e das classes dominantes, "implica o aumento do grau de consciência política dos cidadãos, o reforço do controle popular sobre a autoridade e o fortalecimento do grau de legitimidade do poder público quando este responde às necessidades reais da população" (BORDENAVE, 1994, p. 21). Para o autor, quando a população participa da fiscalização dos serviços públicos, estes tendem a melhorar sua qualidade.

Todavia, é importante ter cuidado com a simples ideia de fiscalização, tendo em vista que, como destaca Shiroma, Garcia e Campos (2011), houve um deslocamento da noção de participação no contexto da "gestão democrática": de produto das lutas dos anos de 1980 para a ideia de "gestão participativa", usada como estratégia de responsabilização (accoutability) em que não se faz menção à participação como partilha de poder. É justamente um dos cuidados que se deve ter quando pensamos a participação, especificamente, quando falamos das ouvidorias públicas, o que mostra as contradições de tê-la, já que, para muitos, é como um balcão de reclamações.

O debate de accoutability é extenso e envolve diversas perspectivas teóricas e históricas, o que fica claro quando lembramos das mudanças na década de 90, mas que essas questões não devem ser aprofundadas neste trabalho, uma vez que não cabem no objetivo. Ainda assim, é um movimento que deve ser considerado, já que também é um fenômeno do gerencialismo, que, por conseguinte, é um produto do neoliberalismo. São inter-relações e uma não exclui a outra.

\section{Análise dos relatórios de gestão entre 2015-2019}

Postos os debates, adentra-se nos objetos de estudo, que são os relatórios de gestão da Ouvidoria-Geral de Pernambuco. As principais dificuldades foram referentes à organização das informações desses relatórios e a falta de padronização dos conteúdos dos documentos, que envolvem gráficos e tabelas. Entendemos que a qualidade desses documentos é um elemento importante para a participação em qualquer espaço, tendo em vista que, se as pessoas não têm acesso ou desconhecem as informações, dificilmente elas podem tomar decisões sobre qualquer questão pública. Outro problema observado foi a falta de padrão na periodicidade de cada relatório, que também impossibilitou um acompanhamento melhor no sentido qualitativo e também quantitativo. 
Sobre essa questão, a Lei de Acesso à Informação (LAI) ou Lei 12.527, de 18 de novembro de 2011, cita no seu artigo $8^{\circ}$ que "é dever dos órgãos e entidades públicas promover, independentemente de requerimentos, a divulgação em local de fácil acesso, no âmbito de suas competências, de informações de interesse coletivo ou geral por eles produzidas ou custodiadas" (BRASIL, 2011), o que é denominado na Gestão Pública de transparência ativa. A Lei ainda especifica em seus requisitos que se deve "IV - divulgar em detalhes os formatos utilizados para estruturação da informação; V - garantir a autenticidade e a integridade das informações disponíveis para acesso" (BRASIL, 2011). Assim, há esses dois elementos importantes, além de a forma como as informações são apresentadas e a antecedência antes de serem solicitadas.

Sobre o relatório de 2015, é possível localizar as informações referentes ao mês de janeiro a dezembro, além de um relatório de Pedidos de Acesso à Informação (PAI), que é apresentado separadamente, mas com poucas informações passíveis de análises mais concretas, por apresentar dados mais quantitativos.

Para sinalizar, o Pedido de Acesso à Informação (PAI), como está presente no Manual de Procedimentos da Rede de Ouvidorias do Poder Executivo de Pernambuco, é uma solicitação direcionada aos órgãos ou entidades públicas, realizada por qualquer pessoa física ou jurídica (como empresas ou associações civis) que tenha por objeto um dado ou informação pública, já a solicitação é um requerimento de ações, procedimentos e projetos à Administração Pública e pedido de instrução, orientação ou comunicação a respeito dos serviços prestados pelo Estado.

No site direto da SEE-PE, é possível verificar que há dois formulários distintos, o de manifestação (reclamação, sugestão, elogios, solicitação, denúncia) e o de pedido, relacionado ao PAI. O problema é que a Secretaria não esclarece se há erros nas categorizações dos usuários ou quais os procedimentos internos adotados para sistematizar essas informações. Pelos próprios termos, é fácil inferir que os usuários podem considerar como sinônimos o PAI e a solicitação e não está claro como se dá o tratamento dessas informações. 
Figura 1 - Consolidado de janeiro a dezembro de 2015

Top 10 - Quantidade de manifestaçöes em 2015

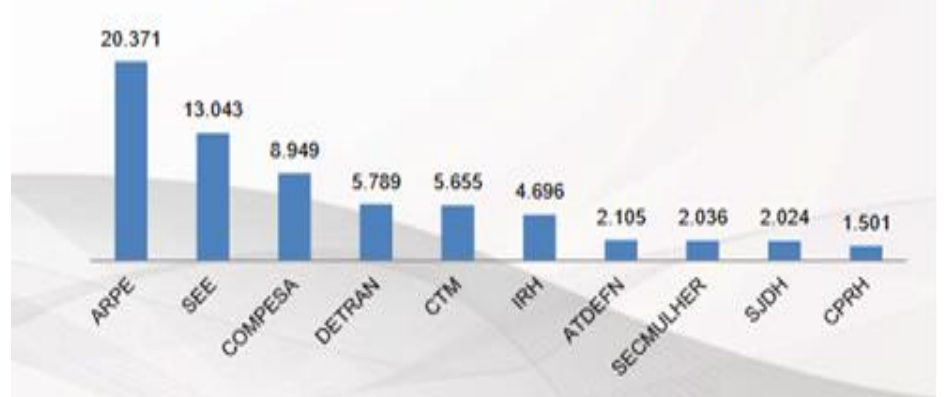

Fonte: Pernambuco (2015)

O relatório específico sobre a Secretaria de Educação sinaliza que o quantitativo por manifestações foram: informações (4.982); solicitações (2.160); denúncias (706); reclamações (3.782); elogios (87); sugestões (71). Portanto, há novamente dúvidas sobre o entendimento semântico de informações e solicitações, que são justamente as maiores demandas. As denúncias, logo depois, aparecem com maior número, seguidas de reclamações.

O relatório de 2016 é parecido ao próximo, de 2017, a diferença está na presença, no primeiro documento, do Relatório Estatístico Rede de Ouvidorias e SIC janeiro a dezembro 2016, o Relatório Estatístico Rede de Ouvidorias e SIC - dezembro 2016 e o Relatório Estatístico Trimestral LAI, que, por serem consolidados, apresentam informações gerais por Secretaria, não o tipo de demanda. A próxima imagem apresenta o consolidado do ano de 2016. Análises qualitativas também não estão presentes nos relatórios, o que temos são as quantidades de denúncias (813); reclamações (3.315); elogios (108); sugestões (75); informações (3.389) e solicitações (5.038).

Imagem 2 - Consolidado 2016

\section{Top 10 - quantidade de manifestações em 2016}

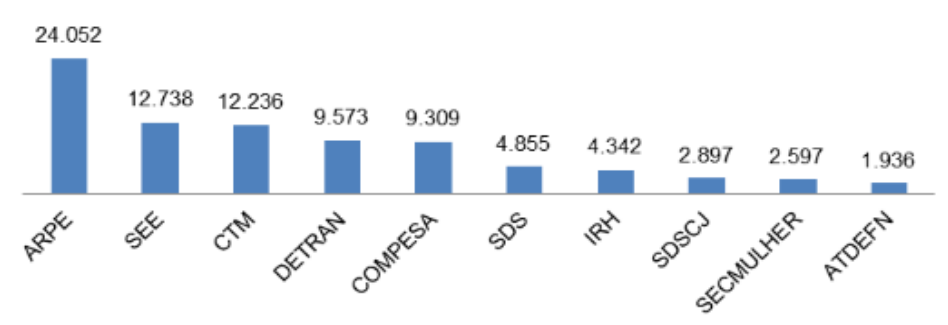

Fonte: Pernambuco (2016)

RPGE- Revista on line de Política e Gestão Educacional, Araraquara, v. 25, n. 2, p. 1173-1191, maio/ago. 2021. e-ISSN: 1519-9029 
Ao que se refere ao relatório de gestão de 2017, a forma com que as informações são apresentadas são distintas do anterior (2016) e do próximo (2018). Primeiro, porque não apresenta um consolidado e, segundo, porque não há um relatório específico sobre o PAI. Inicialmente, a proposta era fazer uma evolução de demandas por ano (2015-2019), todavia, com a falta de padrão e explicação das metodologias quantitativas mais claras, optou-se por fazer uma análise apenas enquanto unidade, não como conjunto.

Imagem 3 - Consolidado de dezembro 2017

Top 10 - Quantidade de manifestações em 2017

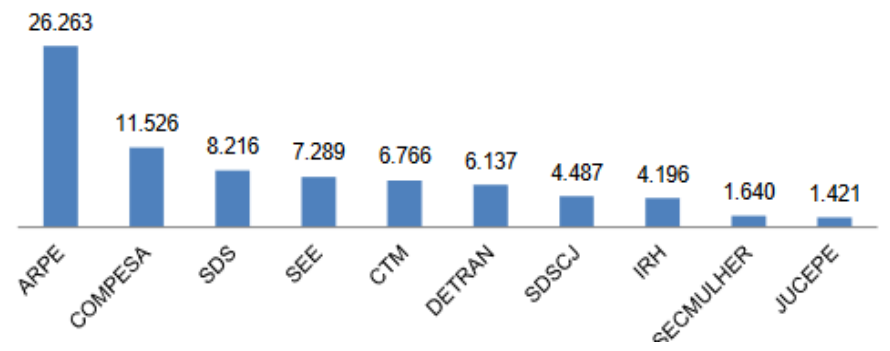

Fonte: Pernambuco (2017)

Uma informação que consta no relatório enquanto nota de rodapé é que "as manifestações anteriormente cadastradas como informação passaram a ter seus registros na natureza solicitação a partir do exercício de 2017 atendendo a recomendação da Rede de Ouvidorias Nacionais" (PERNAMBUCO, 2017, p. 2). Ou seja, a problemática apontada no relatório anterior, foi prevista enquanto questão em 2017, ainda assim não foi esclarecido em manuais ou cartilhas os procedimentos internos de categorização. No site direto da Ouvidoria do SEE-PE, ainda existem os dois campos (PAI e manifestações) e não fica claro como a Ouvidoria-Geral trata as informações de cada orgão.

O relatório de 2018 apresenta as principais formas de contato, figurando a internet como a mais utilizada. Os dados do relatório de 2018 apontam sobre as formas de contato com a Ouvidoria que 3.812 usuários usaram a internet; 1.726 deles, o 0800; 268, o e-mail; 168, o 162; 59 foram presencialmente; 4 utilizaram o disque-denúncia; 3 escreveram cartas; 1 utilizou o reclame aqui; e 1, o aplicativo. Não fica claro no relatório como se deu o processo de encaminhamento de contato pelos quatro últimos canais. É possível inferir que, se a internet é a principal fonte de contato, também é passível de ser a principal fonte de consulta das informações, onde incide a problemática sobre transparência ativa. Os tipos de 
informações mais requeridos foram: reclamação, com 2.673 demandas; solicitação, com 2.105; denúncia, 856; pedido de acesso à informação, 295; elogio, 72; e sugestão, 41.

O relatório também apresenta uma análise das manifestações recorrentes e/ou relevantes, conforme consolidado no Quadro 1. O problema é que não é possível, através dos relatórios, definir, por exemplo, no campo Gestão Escolar, se o mesmo é resultado quantitativamente de qual manifestação, ou seja, se são reclamações, elogios, sugestões ou demais. Supondo que a questão esteja interligada com o campo de reclamações, temos então diversas situações, a dúvida que fica se refere às ações tomadas com as informações produzidas pela ouvidoria. São usadas como fontes para componentes na formação desses profissionais? São apresentadas através de consolidados aos gestores escolares? Como são tratadas enquanto feedback? É possível então perceber um espaço para pesquisa, para a gestão do conhecimento na rede da SEE-PE, todavia, resta saber como ocorre na prática, já que as informações são genéricas nos próprios relatórios.

Quanto às outras manifestações, como matrícula e histórico escolar, figura o seguinte questionamento, como é na prática a questão da gestão documental nos espaços escolares e no site da Secretaria da Educação? Como é possível observar, temos aqui uma relação com o que foi visto como transparência ativa, ou seja, que autoriza o acesso independente da demanda externa, mas, para isso, é preciso as informações estejam disponíveis. Além disso, podemos também questionar a comunicação e as dificuldades de acesso dos usuários.

Quadro 1 - Síntese das manifestações recorrentes e/ou relevantes (2018)

\begin{tabular}{|c|c|c|}
\hline Assunto & Objeto/Teor & Providências Adotadas \\
\hline Gestão Escolar & $\begin{array}{l}\text { Reg istros de comunidade esc olar } \\
\text { sobre situações que ocorrem na } \\
\text { gestãoda escola eno dia a dia do } \\
\text { anbiente escolar. }\end{array}$ & 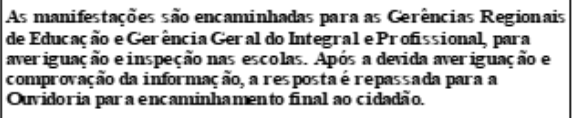 \\
\hline $\begin{array}{l}\text { Pedido de } \\
\text { Ac esso à } \\
\text { Informnçãão }\end{array}$ & $\begin{array}{l}\text { Reg istros realizados de acordo com a } \\
\text { Lei de Ac esso à Informação, onde } \\
\text { cidadãos solic itam dados referentes a } \\
\text { informaçôes públicas da Secretaria } \\
\text { de Educação. }\end{array}$ & 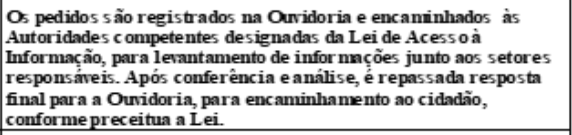 \\
\hline $\begin{array}{c}\text { Concursol } \\
\text { Seleç ão } \\
\text { Contr ataç ão } \\
\end{array}$ & $\begin{array}{l}\text { Reg istros de cidadãos que desejam } \\
\text { atuar como pr ofissionais Secretaria } \\
\text { de Educaçãos obre informaç̃es e } \\
\text { questionamentos sobre seleçóes em } \\
\text { geral e conc ursos, encer rados ou em } \\
\text { andamento ou que já foram } \\
\text { encerr adas, divulgadas no site da } \\
\text { Secretaria. } \\
\end{array}$ & $\begin{array}{l}\text { É commicado inic ialmente ao cidadão que as infornnções gerais } \\
\text { se encontram noEdital da selecãó. Caso o cidadão permameça com } \\
\text { adúvida, seu questionamentos erá registrado e encaminhado aos } \\
\text { setores devidos, par a posterior envio da resposta ao indivíduo. }\end{array}$ \\
\hline Matrícula & $\begin{array}{l}\text { Ques tionamentos quanto ao process o } \\
\text { dec adastro de matr ícula es ituações } \\
\text { das vagas nas escolas da Rede } \\
\text { Estadual de Pernambuco. }\end{array}$ & $\begin{array}{l}\text { As manifestações referentes ao processo de matrícula escolar } \\
\text { são encaminhadas às Gerências Regionais de Educaç ão eà } \\
\text { gerênc ia da Secretaria responsárel para matricula, para } \\
\text { providênc ias urg entes, de acor do com o pr azo de mntricula. }\end{array}$ \\
\hline $\begin{array}{l}\text { Alumos - } \\
\text { Selecóoes, } \\
\text { Estágios e } \\
\text { Projetos }\end{array}$ & $\begin{array}{l}\text { Registro de estudantes que desejam } \\
\text { participar de estágios es elec óes } \\
\text { referentes aos progr anns ofer tados } \\
\text { pela Sercetaria de Educ acão. Ex PF } \\
\text { no Campus, Programn Ganhe o } \\
\text { Mundo }\end{array}$ & 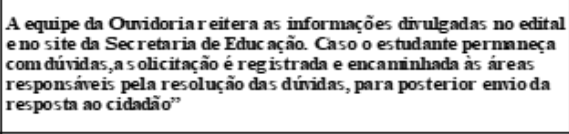 \\
\hline $\begin{array}{l}\text { Histórico } \\
\text { Escolar }\end{array}$ & $\begin{array}{l}\text { Registros de alumos e ex-alumos, } \\
\text { referentes à entreg a de histórico } \\
\text { escolar em escolas que já foram } \\
\text { fechadas ou escolas que estão em } \\
\text { funcionamento. }\end{array}$ & 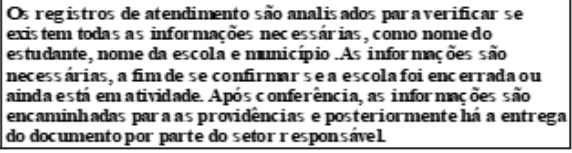 \\
\hline
\end{tabular}

Fonte: Pernambuco (2018) 
Já o relatório de Gestão Anual na Rede de Ouvidorias (2019), comparado aos demais dos anos anteriores, como será visto, pode ser considerado o mais avançado na consolidação das informações e na organização delas. Ele começa com a apresentação de um consolidado de todos os dados gerais das ouvidorias, com um comparativo anual entre 2015-2019, os tipos de manifestações e formas de contatos. Como destaca o documento, "os dados por Órgão/Instituição estão apresentados na seguinte ordem: I. Manifestações por tipo; II. Manifestações por forma de contato; III. Manifestações recorrentes e/ou relevantes e providências adotadas" (PERNAMBUCO, 2019).

Os dados apontam para o fato de que: 3.449 (42\%) foram solicitações; 3.019 (36\%), reclamações; 1.326 (16\%), denúncias; 363 (4\%), acesso à informação; 91 (1\%), sugestões; 47 (1\%), elogios. As principais formas de contato foram pela internet (4274) e o 0800 (3548); seguidos de e-mail (293); caixa de sugestão/OGE (80); presencial (58). Como é possível observar, disque-denúncia, carta, reclame aqui e aplicativo não tiveram registro de contato ou não foram apresentados pelo quantitativo. Em seguida, é apresentado um quadro com Manifestações Recorrentes e/ou Relevantes e Providências Adotadas, como no relatório de 2018.

O primeiro assunto recorrente é sobre a gestão/escola, sinalizado como "registros da comunidade escolar, professores, alunos, pais, etc., sobre situações que geram conflitos na escola, de acordo com as decisões tomadas pela gestão da escola e que repercutem no dia a dia escolar" (PERNAMBUCO, 2019, p. 167). As providências adotadas são:

Os assuntos referentes a situações ocorridas com a gestão da escola são encaminhados para as Gerências Regionais de Educação responsáveis pelas escolas de sua jurisdição ou para a Secretaria-Executiva de Educação Integral e Profissional, para análise e averiguação dos fatos relatados na manifestação. Após a devida averiguação pelas áreas responsáveis pelo assunto em questão, é enviada a resposta final à Ouvidoria, que após análise da resposta com os devidos parâmetros de impessoalidade e cordialidade, é concluído para encaminhamento final ao cidadão (PERNAMBUCO, 2019, p. $67)$.

Como é possível observar, é a mesma lógica de fluxo das ações, sem maiores detalhamentos do relatório de 2018. Outro item que não estava presente no relatório anterior e figurou no do ano de 2019 foi o Desempenho e Comportamento do Professor, onde o objetivo e o teor são "questões relacionadas a situações ocorridas na sala de aula entre professores e alunos. São decorrentes de comportamentos e atitudes de professores, bem como os conflitos existentes no dia a dia, que são registrados pelos alunos e profissionais da escola” (PERNAMBUCO, 2019, p. 67). Ainda assim, o conteúdo resume-se a uma pesquisa 
mais aprofundada para avaliar o comportamento e desempenho do professor e se está sendo mais categorizado como reclamação ou denúncia. As providências tomadas sinalizadas foram:

As manifestações recebidas são devidamente encaminhadas para a área responsável averiguar a veracidade da informação, que após ciência da gestão escolar, a situação possa ser resolvida com os envolvidos. Após a devida averiguação, é encaminhada a conclusão da demanda a Ouvidoria para envio ao cidadão (PERNAMBUCO, 2019, p. 67).

Matrícula, que estava no anterior, e com os mesmos questionamentos quanto ao processo de cadastro e sobre a disponibilidade de vagas nas escolas da Rede Estadual de Ensino de Pernambuco, tem como registro das providências adotadas informações mais detalhadas, de ações mais ágeis, não está demasiadamente generalista como o relatório anterior. Outro ponto de destaque são os registros sobre "concursos e seleções ocorridas durante o ano na Secretaria. São questionamentos de profissionais que desejam obter informações sobre resultados de seleções que já foram encerradas, que estão em andamento, e divulgadas no site da Secretaria de Educação e Esportes" (PERNAMBUCO, 2019, p. 68). Esse ponto também estava presente no relatório de 2018, sendo as ações as mesmas descritas em 2019.

A questão do EAD (Educação a Distância) não estava presente anteriormente, mas aparece no relatório de 2019 sobre a educação profissional, citando "registros de alunos sobre dificuldades de acesso ao sistema e ao site, para conclusão de suas tarefas" (PERNAMBUCO, 2019, p. 68).

Portanto, após a apreensão dos conteúdos e organização dos relatórios, é possível observar que, nos de 2015 até 2017, a preocupação era apresentar informações mais estatísticas, sem maiores apreensões qualitativas. Em 2018 e 2019, são visíveis os esforços para consolidações e análises mais qualitativas, porém sem aprofundamentos, tendo somente a informação e como estão sendo utilizados os dados para melhorar a educação no estado, seja enquanto fonte para formação, seja para tomada de decisão em políticas públicas locais.

\section{Considerações finais}

A dúvida maior que fica ao término deste trabalho é justamente o que é feito com as informações produzidas. Como previsto, o artigo propôs analisar os relatórios de gestão da Ouvidora-Geral do Estado de Pernambuco (OGE). Apenas em um processo de pesquisa mais laborioso, com entrevistas e acompanhamento de documentos internos e fluxos internos, seria possível apreender mais densamente as questões levantadas. 
Sobre o tratamento das manifestações nos relatórios, foi possível observar um grande quantitativo de informações e solicitações, porém a dúvida que surgiu durante a pesquisa, diante da similaridade dos termos, foi como esses dados foram categorizados a partir das solicitações dos usuários, uma vez que a forma com que as informações são tratadas podem interferir diretamente nos dados quantitativos e qualitativos apresentados.

Sobre a organização da informação, está claro que ainda há limites, mas percebe-se avanços internos na categorização de relatórios mais elaborados, principalmente nos relatórios de 2018 e 2019. Porém, pelas demandas apresentadas, entende-se que é um movimento de dupla via, no qual a transparência ativa precisa ser um objetivo geral, em conjunto com as análises e sistematizações das informações produzidas pelos cidadãos, garantindo uma participação ativa e receptiva.

Outro ponto importante é o fato de os relatórios não apresentarem informações mínimas sobre como os dados gerados pela ouvidoria do SEE-PE estão contribuindo para uma melhor Gestão Pública através dos registros dos cidadãos, ou seja, enquanto instrumento de participação. Como apresentado anteriormente por meio de Vaz e Pires (2011), como esses dados provocam impacto na atuação do governo?

Por fim, entendemos que, de fato, com os autores estudados, é difícil avaliar os efeitos da participação, em qualquer canal ou espaço, mas a organização e definição de fluxos de informações faz parte do processo. Encerramos, portanto, em concordância com Gohn (2007) de que deve haver o acesso dos cidadãos às informações que lhes digam respeito. $\mathrm{O}$ estímulo à criação e desenvolvimento de meios democráticos de comunicação são importantes e entendemos as ouvidorias como um deles. Assim, ouvidorias, enquanto espaço de participação, precisam ser conquistadas e ainda estamos longe, mas são o primeiro passo enquanto debate teórico.

\section{REFERÊNCIAS}

BORDENAVE, J. E. D. O que é participação. 8. ed. São Paulo: Brasiliense, 1994.

BRASIL. Constituição da República Federativa do Brasil de 1988. Disponível em: http://www.planalto.gov.br/ccivil_03/Constituicao/Constituiçao.htm. Acesso em: 1 jan. 2018.

BRASIL. Lei n. 12.527, de 18 de novembro de 2011. Regula o acesso a informações previsto no inciso XXXIII do art. $5^{\circ}$, no inciso II do $\S 3^{\circ}$ do art. 37 e no $\S 2^{\circ}$ do art. 216 da Constituição Federal; altera a Lei no 8.112, de 11 de dezembro de 1990; revoga a Lei no 11.111, de 5 de maio de 2005, e dispositivos da Lei no 8.159, de 8 de janeiro de 1991; e dá outras providências. Brasília, DF, 2011. Disponível em: 
http://www.planalto.gov.br/ccivil_03/_ato2011-2014/2011/lei/112527.htm. Acesso em: 04 out. 2019.

CASTRO, A. M. D. A. Administração gerencial: a nova configuração da gestão da educação na América Latina. RBPAE, v. 24, n. 3, p. 389-406, set./dez. 2008. Disponível em:

https://repositorio.ufrn.br/jspui/bitstream/123456789/20387/1/Administra\%C3\%A7\%C3\%A3 o\%20gerencial_2008.pdf. Acesso em: 20 mar. 2020.

CORTES, S. V. As diferentes instituições participativas existentes nos municípios brasileiros. In: PIRES, R. (Org). Efetividade das instituições participativas no Brasil: estratégias de avaliação. Brasília, DF: IPEA, 2015.

DEMO, P. Participação é conquista: noções de política social participativa. 6. ed. São Paulo, SP: Cortez, 1993.

ENAP. Resolução de Conflitos Aplicada ao Contexto das Ouvidorias. Brasília, DF, 2017. Disponível em: https://repositorio.enap.gov.br/bitstream/1/3156/1/M\%C3\%B3dulo\%202\%20$\% 20 \mathrm{~A} \% 20$ ouvidoria $\% 20 \mathrm{p} \% \mathrm{C} 3 \%$ BAblica $\% 20$ como $\% 20$ espa $\%$ C3\%A7o $\% 20 \mathrm{de} \% 20$ excel $\% \mathrm{C} 3$ $\%$ AAncia $\% 20$ para $\% 20 \mathrm{a} \% 20$ resolu $\% \mathrm{C} 3 \%$ A7\%C3\%A3o\%20de $\% 20$ conflitos.pdf. Acesso em: 14 nov. 2019.

GIL, A. C. Como elaborar projetos de pesquisa. 4. ed. São Paulo, SP: Atlas, 2002.

GOHN, M. G. Conselhos gestores e participação sociopolítica. São Paulo, SP: Cortez, 2007.

GOHN, M. G. Teorias sobre a participação social: desafios para a compreensão das desigualdades sociais. Caderno C R H, Salvador (BA), v. 32, n. 85, p. 63-81, jan./abr. 2019. Disponível em: http://www.scielo.br/scielo.php?script=sci_arttext\&pid=S010349792019000100063. Acesso em: 12 out. 2019.

GOMES, M. E. C. Do instituto do ombudsman à construção das ouvidorias públicas no Brasil. In: LYRA, R. P. (Org.) A Ouvidoria na Esfera Pública Brasileira. Curitiba, PR: UFPR, 1996.

HOFLING, E. M. Estado e políticas (públicas) sociais. Cad. CEDES, v. 21, n. 55, p. 30-41, 2001. Disponível em: https://www.scielo.br/pdf/ccedes/v21n55/5539.pdf. Acesso em: 14 jul. 2020.

JARDIM, J. M; SILVA, S. C A; NHARELLUGA, R. S. Análise de políticas públicas: uma abordagem em direção às políticas públicas de informação. Perspectivas em Ciência da Informação, Belo Horizonte (MG), v. 14, n. 1, p. 2-22, jan./abr. 2009. Disponível em: http://www.scielo.br/pdf/pci/v14n1/v14n1a02.pdf. Acesso em: 17 ago. 2019.

LAVALLE, A. G. Participação: Valor, Utilidade, Efeitos e Causa. In: PIRES, R. R. A. (Org.). Efetividade das instituições participativas no Brasil: estratégias de avaliação. Brasília, DF: Ipea, 2011.

LIMA, C. S. Ouvidoria pública no Estado de Pernambuco: passos na perspectiva da cidadania. 2008. Dissertação (Mestrado Profissional em Gestão Pública para o 
Desenvolvimento do Nordeste) - Centro de Ciências Sociais Aplicadas, Universidade Federal de Pernambuco, Recife, 2008.

MILANI, C. R. S. O princípio da participação social na gestão de políticas públicas locais: uma análise de experiências latino-americanas e europeias. RAP-Revista de Administração Pública, Rio de Janeiro (RJ), v. 42, n. 3, p. 551-579, maio/jun. 2008. Disponível em: http://www.scielo.br/scielo.php?pid=S003476122008000300006\&script=sci_abstract\&tlng=pt. Acesso em: 10 nov. 2019.

NASCIMENTO, C. M. M. O Estado Escuta a Educação Escolar? A ouvidoria educacional como componente da política educacional mineira. 2012. Dissertação (Mestrado Acadêmico em Educação) - Pontifícia Universidade Católica de Minas Gerais, Belo Horizonte, 2012.

NETO, F. L; DURÁN, P. R. F. Ouvidorias públicas e conselhos de políticas: avanços e desafios na democratização da participação social e nas relações entre estado e sociedade. In: MENEZES, R. A; CARDOSO, A. S. R. (Org.) Ouvidoria pública brasileira: reflexões, avanços e desafios. Brasília, DF: Ipea, 2016.

PERNAMBUCO. Decreto n. 32.476, de 14 de outubro de 2008. Dispõe sobre a criação da Ouvidoria Geral do Estado, e dá outras providências. Disponível em: http://legis.alepe.pe.gov.br/texto.aspx?id=7982\&tipo=TEXTOORIGINAL. Acesso em: 17 ago. 2020.

PERNAMBUCO. Lei n. 16.420, de 17 de setembro de 2018. Dispõe sobre participação, proteção e defesa dos direitos do usuário dos serviços públicos da administração pública estadual. Disponível em:

https://legis.alepe.pe.gov.br/texto.aspx?tiponorma=1\&numero $=16420 \&$ complemento $=0 \&$ ano $=2018 \&$ tipo $=\& u r l=$. Acesso em: 14 mar. 2020 .

PERNAMBUCO. Relatório Estatístico da Rede de Ouvidorias e SIC 2016. Disponível em: http://www.ouvidoria.pe.gov.br/wp-content/uploads/2019/02/Relat\%C3\%B3rio-

Estat\%C3\%ADstico-Rede-de-Ouvidorias-e-SIC-Janeiro-a-Dezembro-2016-1.pdf. Acesso em: 15 mar. 2020.

PERNAMBUCO. Relatório Estatístico da Rede de Ouvidorias e SIC dezembro 2017.

Disponível em: http://www.ouvidoria.pe.gov.br/wp-

content/uploads/2019/02/Relat\%C3\%B3rio-da-Rede-de-Ouvidoria-e-SIC-Dezembro-20171.pdf. Acesso em: 13 maio 2020.

PERNAMBUCO. Relatório Estatístico Rede de Ouvidorias e SIC janeiro a dezembro 2015. Disponível em: http://www.ouvidoria.pe.gov.br/wpcontent/uploads/2019/02/Relat\%C3\%B3rio-Estat\%C3\%ADstico-Rede-de-Ouvidorias-e-SICJaneiro-a-Dezembro-2015-1.pdf. Acesso em: 14 maio 2020.

SEVERINO, A. J. Metodologia do trabalho científico. 23. ed. São Paulo, SP: Cortez, 2007.

SHIROMA, E; GARCIA, R. M. C; CAMPOS, R. F. Conversão das "almas" pela liturgia da palavra: uma análise do movimento Todos pela Educação. In: BALL, S. J.; MAINARDES, J. Políticas educacionais: questões e dilemas. São Paulo, SP: Cortez, 2011. 
SOARES, M. C. C. O Banco Mundial, Políticas e Reformas. In: DE TOMASI, L.; WARDE, M. J.; HADDAD, S. (Org.). O Banco Mundial e as políticas educacionais. São Paulo, SP: Cortez, 1996.

VAZ, A. C. N.; PIRES, R. R. C. Comparações entre municípios: avaliação dos efeitos da participação por meio de pares contrafactuais In: PIRES, R. (Org.). Efetividade das instituições participativas no Brasil: estratégias de avaliação. Brasília, DF: Ipea, 2011.

\section{Como referenciar este artigo}

OLIVEIRA, D.S; ARRUDA, A. L. B Ouvidoria-Geral do Estado de Pernambuco: análise dos relatórios de gestão da Secretaria Estadual de Educação (2015-2019). Revista on line de Política e Gestão Educacional, Araraquara, v. 25, n. 2, p. 1173-1191, maio/ago. 2021. eISSN:1519-9029. DOI: https://doi.org/10.22633/rpge.v25i2.14862

Submetido em: 10/03/2021

Aprovado em: 28/05/2021

Publicado em: 01/08/2021 